\title{
Reaching goals through different means: will and cognition in the action of people with low and high action control
}

\author{
Konrad Ariel Hryniewicz (D) $1 \cdot A, B, C, D, E, F$, fudyta Borchet (D) $2 \cdot B, E, F$ \\ 1: SWPS University of Social Sciences and Humanities, Warsaw, Poland \\ 2: Institute of Psychology, University of Gdansk, Poland
}

\section{BACKGROUND}

When observing how people strive to achieve their goals, we can discern two main styles. Some people accomplish their goals mainly through strong will while others may need additional and compound plans to rely on. Two different modes of implementation of intentional behavior are explored.

PARTICIPANTS AND PROCEDURE

Two correlational studies on young Polish adults $(N=227$ and $N=516$ ) were performed. Structural equations and modeling techniques using the partial least squares (PLS) method were used to verify the predictions.

\section{RESULTS}

The first investigation revealed that the intention of saving money is achieved through the mechanism of implementation intention. It was found that people with a low level of action control (state-orientation) and people with a high level of action control (action-orientation) imple- ment a similar level of saving behavior. However, they do so in different ways. Action-oriented participants also seemed to make plans, and these plans supported goal attainment, though this process did not affect behavior to the same degree as for state-oriented participants. The results are discussed, drawing on the Julius Kuhl Action Control Theory as well as its explication which is the Theory of Personality Systems Interactions.

\section{CONCLUSIONS}

The present research indicates that cognitive mechanisms may compensate for volitional deficits (planning behavior) in people with low action control, whereas in the case of people with a high level of action control their will (intensification of intentions) plays a crucial role.

\section{KEY WORDS}

SEM-PLS; action control; saving; implementation intention; individual differences

CORRESPONDING AUTHOR - Konrad Ariel Hryniewicz, SWPS University of Social Sciences and Humanities,

19/31 Chodakowska Str., 03-815 Warsaw, Poland, e-mail: khryniewicz2@st.swps.edu.pl

AUthors' CONTRIBUtion - A: Study design - B: Data collection - C: Statistical analysis - D: Data interpretation .

E: Manuscript preparation · F: Literature search · G: Funds collection

TO CITE this ARTICLE - Hryniewicz, K. A., \& Borchet, J. (2019). Reaching goals through different means: will and cognition

in the action of people with low and high action control. Current Issues in Personality Psychology, 7(4), 274-287.

RECEIVED 21.05.2019 · REVIEWED 29.08.2019 • ACCEPTED 05.09.2019 · PUBLISHED 27.09.2019 


\section{BACKGROUND}

There seem to be two main ways of how people strive to achieve their goals. Some people accomplish their goals mostly through a strong will, while others mainly rely on their plans. The former group is clearly spurred into action by the sole purpose of attaining their goal, whereas the latter group is led to goal accomplishment by cognitive organization. In the article, we indicate that the above-mentioned modes of operation depend on the level of exercising control over one's behavior (see more about action control: Kuhl, 1984, 2000). People with a high level of control (action-oriented) fulfill their intentions mainly because they want it. In the case of those who have difficulty with control (state-oriented), the pursuit of the goal is supported by planning. We present the results of two questionnaire studies concerning the mediating role of a plan (the mechanism of intention implementation) and its relations to the intention to save, a saving lifestyle, and the amount of savings. In the first study, we found that planning is a distinguishable mechanism which mediates between the intention to save and a saving lifestyle. In the second study, we observed that in the case of state-oriented people planning was more important than the intention in the course of realizing a saving lifestyle and the amount of savings. However, in the case of action-oriented people the intention had greater importance than planning when predicting saving and the amount of savings.

\section{IMPLEMENTATION INTENTION AND REDUCED CONTROL OVER BEHAVIOR}

As assumed by most social-cognitive theories, an intention for the desired behavior is its best predictor (Ajzen, 1985; Prochaska, Wright, \& Velicer, 2008; Steinmetz, Knappstein, Ajzen, Schmidt, \& Kabst, 2016). These theories explain the strength of the intention itself, but they are less able to predict whether actual action will follow the intention (Schwarzer, 2008). What they take into account is just the fact that an intention may change with the passage of time, while they fail to consider the notion that people differ in their ability to control intentional behavior. Despite a clearly stated intention towards behavior and a strong motivation to perform it, people often abandon it or act contrary to it. The causes of failures in intention realization may fall into such categories as individual differences in action control (see Kuhl, 1984, 2000), unforeseen difficulties, succumbing to temptations, laziness, and the lack of mental abilities to act at all (Kuhl, 1984, 2000; Muraven, Tice, \& Baumeister, 1998; Schwarzer, 2008). In the face of such difficulties, Kuhl (1981, 2000, 2001) points out that intention realization must be supported by the personality control system of one's own behavior. Without activation of this system, an intention is represented only in memory, not in action (Goschke \& Kuhl, 1993). In such a case, a person thinks about the behavior she/he wants to perform, but she/he lacks the possibility to coordinate the supervision over its implementation, which is a classic example of weakened control over intentional behavior. This stalemate situation of the lack of control over one's own actions Kuhl (1984) describes as state orientation and emphasizes that it is a non-pathological form of depression.

State-oriented people (characterized by reduced action control) realize their intentions with less vigor and ease than people who are action-oriented (characterized by increased action control) (Kazén, Kuhl, \& Leicht, 2014). It may seem that state-oriented people may perform worse in intention realization and maintaining control over their own behavior than those who are action-oriented. Nevertheless, we consider that there exists a mechanism that supports state-oriented people in exercising control over intention realization: planning. This mental process helps with undertaking effective actions and intention realization (Gollwitzer \& Sheeran, 2006; Schwarzer, 2008). Planning allows people to perform a mental simulation of the conditions, time, and manners of behavior as if in the real circumstances in their memory. The transition from state orientation into action orientation can be supported by the formulation of an intention in the form of the appropriate plan. In the literature, planning is a psychological mechanism defined as the ability to implement intentions (Gollwitzer, 1999). It consists in setting up an action plan in memory, which refers to "When?", "How?" and "Where?" regarding the performance of the desired behavior. We believe that, as a result of such preparation, people with a low level of action control can perform the desired behavior as well as people with a high level of action control.

\section{IMPLEMENTATION INTENTION AS A BEHAVIOR CONTROL MECHANISM}

An intention to act is one of the main determinants of the desired behavior (Ajzen, 1985, 1991); however, it may be too weak to facilitate the behavior on its own. It might require the support of mechanisms enabling the implementation of the behavior. Without the assistance of other psychological mechanisms, an intention may be more like a manifestation of the willingness to act than a warranty for the realization of the desired behavior (Ajzen, 1985). We propose one of the possible ways to control behavior, which explains the processes behind successfully fulfilled intentions: it is a simple action plan which is the formulation of how to implement an intention (Gollwitzer, 
1999). An implementation intention is the creation of a plan for "When?", "Where?" and "How?" regarding the performance of the desired behavior. The desirable behavior developed in such a way is more than just a simple formulation of the action plan: it allows people to create in advance a cognitive representation of circumstances in which a previously prepared sequence of behaviors can be performed (Schwarzer, 2008). If any of the elements of the implementation structure is encountered and recognized, the action prepared in this way can be performed efficiently and automatically (Gollwitzer, 1999): When I suddenly feel positive emotions in the store, I should be more careful in shopping and spend money just for what I came for. The meta-analysis of the research on implementation intention showed that planning one's behavior in an implementing manner has a pronounced impact on achieving many goals, including consumer goals (Gollwitzer \& Sheeran, 2006).

\section{DEGENERATED INTENTION}

An implementation intention may prevent the formation of a degenerated structure of intention, which often appears in state-oriented people. Kuhl describes a degenerated intention as a cognitive structure representing a defective intention which leads to a failure in behavior. In a degenerated structure of intention, one or more of the elements of intention realization are ill-defined, poorly activated, or not specified at all (Kuhl, 1984). Such a degenerated form of intention to behave can be observed precisely when someone is experiencing surprise, e.g. due to an unexpectedly low price of a blender spotted while shopping. In the first moments of such a situation, the person would probably stop thinking about their original intentions to do the necessary grocery shopping. Instead, his/her memory might be filled with thoughts about the unprecedented opportunity to buy a high-quality blender, and the consideration of various alternatives for acting in such a situation; he/she might not take into account his/her low account balance. Such a degenerated intention does not allow a desirable behavior to happen in a particular situation and causes momentary helplessness that activates state orientation instead of action orientation. It is a state of an organism in which a defective structure of intentions dominates cognition, leads to reduced control of the action, a relative weakening of memory functioning as well as failures in the performance of one's intentions (Kuhl, 1984, 2001).

Based on the above, we predict that the mechanism of implementation intention compensates for behavioral deficits which result from the effects of experiencing a degenerated intention while being subjected to state orientation. We presume that this form of planning plays a significant role in intention- al behavior control, and it is of particular importance for people with low levels of action control.

\section{INDIVIDUAL DIFFERENCES IN ACTION CONTROL AND IMPLEMENTATION INTENTIONS}

State orientation, as well as action orientation, can be considered not only situationally, but also as a general trend in one's functioning. Both can be seen as relatively constant individual differences in behavior. Action orientation is a dominant activity that includes focusing on achieving goals, quick selection of one of the action alternatives, planning, and motivating (Baumann \& Kuhl, 2005; Baumeister \& Vohs, 2007). This orientation supports behavior realization, because it reduces the discrepancy between the current intention and the expected state, whereas state orientation is a tendency for a cognitive activity which manifests itself as ruminations focused on the current state of the organism, distraction, thinking about past failures, and hesitation when making decisions (Kuhl, 1981, 1984).

Action-oriented people have a greater potential to fulfill intentions than those who are state-oriented. They realize the intentions while having the memory free from intrusive thoughts unrelated to the intended behavior, and due to stronger will and energy for action (Kuhl, 1984; Kazén et al., 2014). However, there are certain circumstances in which state-oriented people can achieve a similar level of achievement and control of their behavior as action-oriented people. This was demonstrated in an experiment in which situations inducing and preventing the manifestation of state orientation were manipulated (Kuhl, 1981). The procedure of this study used the method of working on the solution of an unsolvable task. As to this experimental manipulation, there is a common agreement among researchers that this type of task effectively induces learned helplessness. This helplessness is interpreted as passivity, the lack of control over the initiation of behavior, and state orientation (Kuhl, 1981, 1984; Maier \& Seligman, 2016; Seligman \& Maier, 1967). In the experiment, it was observed that people who were saying their hypotheses on how to solve an unsolvable task out loud, did not experience the deficit of behavior which ensues from state orientation. The result was that when performing the second task, this time fully solvable, these people achieved similar results to those who were not affected by induced helplessness. The act of saying the hypotheses out loud prevented the emergence of mind-bearing thoughts such as coming up with reasons for succeeding or failing, thinking of one's own feelings, reflecting on being puzzled. This allowed the subjects to protect themselves from the adverse effects accompanying state orientation and 
to perform the next task without much difficulty (Kuhl, 1981). We believe that a similar mechanism of protection against the negative consequences of state orientation is the mechanism of implementation intention. It can counteract the difficulties encountered while striving to achieve goals.

In our opinion, planning one's behavior may prevent the emergence of degenerated intentions such as helplessness, hesitation as well as ruminations on the circumstances conducive to the implementation of the desired behavior. We assume that, if people experiencing state orientation frequently plan their behavior ahead, they will be able to make decisions faster, their thoughts will have an ordered structure, and their response will remain organized (Kuhl, 1984, 2001). State-oriented people who implement their plans this way will be prepared for the problems related to cognitive disturbances which they tend to experience. They will be able to realize intentional behavior at a similar level to the performance of people who are action-oriented. Their cognitive preparation for action will allow them to control their behavior.

\section{THE IMPORTANCE OF ACTION CONTROL IN THE AREA OF PERSONAL FINANCES}

The concept of controlling intentional actions in the area of saving behaviors is of particular importance. Research indicates that control of one's behavior plays a crucial role in the context of consumer decisions and financial activities (Baumeister, 2002; Faber \& Vohs, 2011; Sotiropoulos \& d'Astous, 2013). Weak action control leads to adverse economic, health, social, and legal consequences (Drever et al., 2015; Taylor, Jenkins, \& Sacker, 2011; von Stumm, Fenton O'Creevy, \& Furnham, 2013; Worthy, Jonkman, \& Blinn-Pike, 2010; Xiao, Chatterjee, \& Kim, 2014). It follows from the above that the ability to control one's behavior is one of the clear determinants of financial behavior as well as its effects. In this study, we assumed that money can effectively be saved by treating saving behavior as an area in which an intention and the control over it are drivers of a financially healthy lifestyle (Dholakia, Tam, Yoon, \& Wong, 2016; Loibl, Grinstein-Weiss, Zhan, \& Red Bird, 2010).

\section{STUDY 1}

The aim of the study was to explore the mechanism of implementation of the intention to save in stateand action-oriented people. We anticipated that people who struggle with action control (state-oriented people) realize their intentions mainly through planning their actions. We also assumed that people with high action control (action-oriented people) imple- ment their intentions mostly through the mere fact of wanting to do so.

\section{PARTICIPANTS AND PROCEDURE}

The study was conducted by an online version of the questionnaire which was displayed to Polish students from various cities through the Facebook Ads service. Those who took part in the study were volunteers. Informed consent was obtained from all individual participants included in the study before they started the questionnaire. The incentive to complete the survey was the possibility to win one of three prizes (a mobile phone, a portable speaker, or headphones). The participants were ensured about their anonymity and that the data were being collected for scientific purposes. After a short introduction that presented the study as research on saving and a part of a Ph.D. project, the participants were presented the set of questionnaires. The survey took from 10 to 15 minutes to complete. In the end, the participants were thanked for their participation in the survey. There were 227 young adults $(M=24.21$, $S D=6.57)$ who took part in the study. The group consisted of 183 women (80.6\%) and 44 men (19.4\%).

\section{MEASURES}

Basic demographic variables as well as the contact details (e-mail) necessary to allow the participants to take part in the next step of this study were collected. Apart from that, the following measures were used.

Intention to save was measured with a modified version of Behavioral Intentions by Schwarzer (2008). The measure is unidimensional and originally concerned health behaviors. In the current study, the items referred to saving money (Schwarzer, 2008). The following statements were used: 1 - I intend to save money; 2 - I intend to reduce the number of unplanned purchases; 3 - I intend to make big savings; 4 - I want to create a money reserve. Each of the statements was ranked on a scale from 1 (not true) to 4 (true). Mean score was the outcome variable.

Implementation of the intention measure was also inspired by Schwarzer's work (2008, see Action Planning scale). Originally, the measure concerned the subject's plans on how to perform health behaviors. For the purposes of the current study, the scale was adjusted for saving money. The following statements were used: 1 - I know in which situations I will be able to save; 2 - I know how to organize my life and expenses to save; 3 - I know in which situations I will be able to save; 4 - I know how to plan my expenses to save; 5 - I know how to organize my life to save; 6 - I know when and how to plan my expenses to both save and live normally. Each of the statements 
Table 1

Measurement properties of the tested variables in Study 1

\begin{tabular}{lcccccc}
\hline$N$ & Variable & $R^{2}$ & $\Delta R^{2}$ & CR & $\alpha$ & AVE \\
\hline \multirow{2}{*}{227} & Intention & - & - & .73 & .67 & .42 \\
& Implementation & .07 & .06 & .88 & .88 & .56 \\
& Saving & .37 & .37 & .88 & .88 & .59 \\
\hline
\end{tabular}

Note. $R^{2}-R$-squared; $\Delta R^{2}$ - adjusted $R$-squared; CR - composite reliability; $\alpha$ - Cronbach's $\alpha$; AVE - average variance extracted

was ranked on a scale from 1 (not true) to 4 (true). Mean score was the outcome variable.

Saving lifestyle, based on the work of Dholakia et al. (2016), was measured in the second stage of this study (which took place 30 days after the first one). The respondents were sent an email and a text message with a link to the survey on measuring the level of a saving lifestyle with the following positions: 1 - I have big savings; 2 - I can manage to create a financial reserve; 3 - My life is organized well enough for me to live normally and be able to save money; 4 - I make savings to deal with future expenses; 5 - I try to save my money diligently. We measured the answers to all the test items on a fourlevel scale: not true, somewhat untrue, somewhat true and true. Mean score was the outcome variable.

The evaluation of the AVE, Cronbach's $\alpha$, and composite reliability coefficients showed that all the measured variables in the tested model were characterized by an acceptable level of reliability. The results are presented in Table 1. The evaluation of the AVE, Cronbach's $\alpha$, and composite reliability coefficients indicated that the measured variables in the tested model were characterized by an acceptable level of reliability. The results are presented in Table 1.

\section{RESULTS}

Structural equation modeling using the PLS (partial least squares) method in the WarpPLS 6.0 software

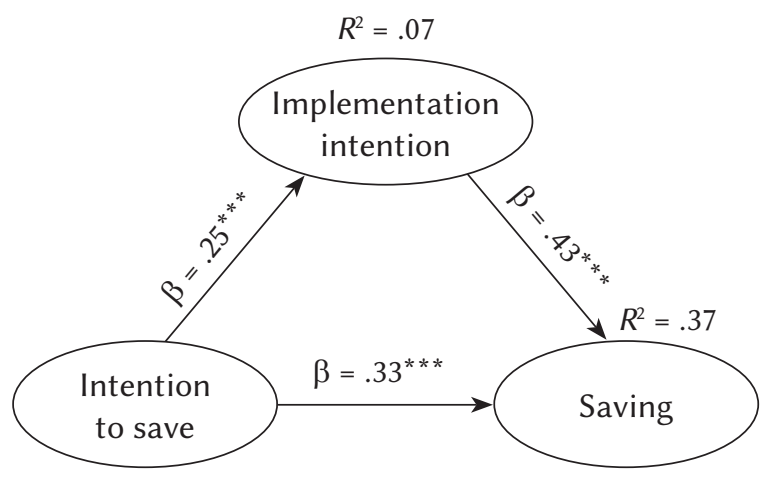

Figure 1. The relationship of the intention to save with its implementation intention and a saving lifestyle.
(Kock, 2010) was performed to analyze the results. The analysis employed the formation of latent variable indicators through the PTH1 algorithm (Kock, 2014a). While estimating the results, this method controls the measurement error of a latent variable based on the value of the Cronbach's $\alpha$ coefficient and does not impose the need to maintain the assumption of independence of the indicators reflecting the latent variable (Kock \& Mayfield, 2015). The analysis indicated that the data fit ${ }^{1}$ very well into the conceptual path model, GoF $=.34$, as well as the measurement model, SRMR $=.08$, SMAR $=.06$ (Iacobucci, 2010; Tenenhaus, Vinzi, Chatelin, \& Lauro, 2005). The collinearity measurements did not show any clear correlations that could burden the estimation of the path coefficients in the model, AVIF $=1.07$, AFVIF $=1.40$ (Kock \& Lynn, 2012). The Simpson paradox ratio (SPR) showed that the path relationships' signs were similar to the independent correlation coefficients between variables, $\mathrm{SPR}=1.00$, and the estimated path values were similar to the values of correlation coefficients, SSR $=1.00$ (Kock \& Gaskins, 2016; Pearl, 2009). The analysis of the path model showed that the intention to save was significantly associated with a saving lifestyle $(\beta=.33$, $p<.001)$ and with intention implementation $(\beta=.25$, $p<.001)$. In turn, intention implementation was significantly associated with the level of a saving lifestyle $(\beta=.43, p<.001)$. In order to verify the mediating effect, an analysis of mediation was performed in the same program (Baron \& Kenny, 1986; Kock, 2011). The analysis showed a significant indirect effect regarding intention implementation, which significantly reduced the direct relation between the intention to save and the level of saving $(\beta=.11$, $p<.01)$. The results are presented in Figure 1 .

\section{SUMMARY}

The analysis of the structural model and reliability coefficients showed satisfactory statistical properties that were the basis for the correct inference from the presented data. It was demonstrated that the intention to save was associated with leading a saving lifestyle due to possessing the ability to formulate intention implementation. 


\section{STUDY 2}

The aim of the study was to replicate the previous mediating effect of intention implementation while taking into account the individual differences in state and action orientation. The research and analytical operations were carried out almost identically to the first study. The only exception was the introduction of measurement of the individual differences related to action control according to Kuhl's concept (1981). He specified three areas in which the observed differences in behavioral control manifest themselves. The first area includes situations in which, while making a decision, one may hesitate or quickly move to action (Decision-related action: orientation vs. hesitation - AOD). The second area pertains to situations of failures after which one can either be preoccupied or act further without worrying about them (Failurerelated action: orientation vs. preoccupation - AOF). The last area is the performance of activities in which one can either manifest instability and distraction behavior in their realization or be entirely absorbed with them (Performance-related action: orientation vs. volatility - AOP).

\section{PARTICIPANTS AND PROCEDURE}

The study was conducted by an online version of the questionnaire which was displayed to Polish students from various cities through the Facebook Ads service. As in the previous study, informed consent was obtained from all individual participants who volunteered to join the study. The incentive to complete the survey was the possibility to win one of three prizes in a lottery (a mobile phone, a portable speaker, or headphones). The participants were ensured about their anonymity and that it was a study on saving money. The whole set of questionnaires took from 15 to 20 minutes to fill in. In the end, the participants were thanked for joining the study. There were 516 young adults aged $24(M=23.83, S D=5.16)$ who took part in the study. $82.9 \%$ of the group were women $(n=427)$ and $17.1 \%$ were men $(n=88)$.

\section{MEASURES}

Action control was measured with the ACS-90 test (Kuhl \& Beckmann, 1994) in Polish adaptation (Marszał-Wiśniewska, 2002). This scale consists of 3 subscales and measures state and action orientation based on the participant's choice of one of two answers which complete the statement in a test item. Answer A indicates state orientation while answer $\mathrm{B}$ points to action orientation. The first subscale is AOD (Decision-related action: orientation vs. hesitation). It refers to decision situations in which one may hesitate or quickly move to action. Sample items are: "When I know I must finish something soon"; Answer A: "I have to push myself to get started"; Answer B: "I find it easy to get it done and over with". The second scale, AOF, refers to situations of failures after which one can either be preoccupied or act further (Failure-related action: orientation vs. preoccupation - AOF). An example from the AOF scale: "When I have lost something valuable and can't find it anywhere"; Answer A: "I have a hard time concentrating on anything else"; Answer B: "I don't dwell on it". The third subscale refers to the performance of activities in which one can either manifest instability and distraction behavior in their realization or be entirely absorbed with them (Performance-related action: orientation vs. volatility - AOP). Sample items of the AOP scale are: "When I'm working on something that's important to me": Answer A: "I still like to do other things in the meantime"; Answer B: "I focus on it so much that I can work on it for a long time".

Savings amount was measured directly. The participants were asked to answer the question: "On average, how much money do you manage to save every month? Enter the amount in PLN". Apart from measuring their savings, it was also the second way of measuring the dependent variable.

The analysis of reliability showed that AOF, AOD and AOP scales were characterized by acceptable and moderate measurement accuracy. Respectively: $\alpha=.75, \alpha=.74, \alpha=.56$. To classify people who are state- and action-oriented, we divided the AOF, AOD and AOP measurements in terms of the median (Kazen, Kuhl, \& Quirin, 2015). The results of the measurement properties of the constructs are presented in Table 2.

\section{RESULTS}

To verify that the model fits the data and the quality of the assessment, we performed structural equation modeling using the PLS method in the WarpPLS 6.0 software (Kock, 2010). The analysis of fit coefficients in every tested subgroup showed that the data fit very well into the conceptualized path models, $\mathrm{GoF}=$ (range: .40-.45), and measurement models, SRMR $=($ range: $.06-.09)$, SMAR $=($ range: .05-.07) $($ Iacobucci, 2010; Tenenhaus et al., 2005). The collinearity measurements did not show elevated correlations that could burden model estimates, AVIF = (range: 1.09-1.29), AFVIF = (range: 1.07-1.59) $($ Kock \& Lynn, 2012). The Simpson paradox ratio showed that the signs path relations were similar to the signs of independent correlations between elaborated variables, SPR $=$ (range: $0.80-1.00$ ), and the values of the estimated path coefficients were similar to the values of correlation coefficients, SSR $=1.00$ (Kock \& Gaskins, 
Table 2

Measurement properties of the tested variables in Study 2

\begin{tabular}{|c|c|c|c|c|c|c|c|c|}
\hline$N$ & Measure & Group & Variable & $R^{2}$ & $\Delta R^{2}$ & $\mathrm{CR}$ & $\alpha$ & AVE \\
\hline \multirow{24}{*}{516} & \multirow{8}{*}{ Decision } & \multirow{4}{*}{ State } & Intention & - & - & .78 & .74 & .47 \\
\hline & & & Implementation & .22 & .22 & .90 & .90 & .60 \\
\hline & & & Saving & .39 & .38 & .87 & .86 & .56 \\
\hline & & & Savings & .07 & .06 & 1.00 & 1.00 & 1.00 \\
\hline & & \multirow{4}{*}{ Action } & Intention & - & - & .75 & .72 & .43 \\
\hline & & & Implementation & .14 & .14 & .87 & .87 & .53 \\
\hline & & & Saving & .51 & .50 & .83 & .83 & .49 \\
\hline & & & Savings & .07 & .06 & 1.00 & 1.00 & 1.00 \\
\hline & \multirow{8}{*}{ Failure } & \multirow{4}{*}{ State } & Intention & - & - & .78 & .74 & .48 \\
\hline & & & Implementation & .19 & .19 & .91 & .91 & .64 \\
\hline & & & Saving & .47 & .46 & .88 & .87 & .59 \\
\hline & & & Savings & .09 & .08 & 1.00 & 1.00 & 1.00 \\
\hline & & \multirow{4}{*}{ Action } & Intention & - & - & .76 & .72 & .44 \\
\hline & & & Implementation & .19 & .19 & .88 & .88 & .56 \\
\hline & & & Saving & .42 & .41 & .84 & .84 & .51 \\
\hline & & & Savings & .04 & .03 & 1.00 & 1.00 & 1.00 \\
\hline & \multirow{8}{*}{ Performance } & \multirow{4}{*}{ State } & Intention & - & - & .79 & .75 & .48 \\
\hline & & & Implementation & .23 & .23 & .90 & .90 & .61 \\
\hline & & & Saving & .39 & .38 & .86 & .86 & .56 \\
\hline & & & Savings & .06 & .05 & 1.00 & 1.00 & 1.00 \\
\hline & & \multirow{4}{*}{ Action } & Intention & - & - & .71 & .68 & .39 \\
\hline & & & Implementation & .08 & .08 & .87 & .87 & .53 \\
\hline & & & Saving & .50 & .50 & .83 & .83 & .50 \\
\hline & & & Savings & .08 & .07 & 1.00 & 1.00 & 1.00 \\
\hline
\end{tabular}

Note. $R^{2}-R$-squared; $\Delta R^{2}$ - adjusted $R$-squared; CR - composite reliability; $\alpha$ - Cronbach's $\alpha$; AVE - average variance extracted

2016; Pearl, 2009). In order to check the differences in the strength of path factors between groups of stateand action-oriented people, a multi-group analysis (MGA) was performed (Kock, 2014b). In order to verify whether the observed differences between the strength of paths resulted from the differences between groups, and not from the differences in the way of measuring the variables studied in the model, an invariance analysis recommended in the context of MGA was performed (Sarstedt, Henseler, \& Ringle, 2011; Sarstedt, Ringle, \& Hair, 2017). The invariance analysis between the state- and action-oriented group, in the areas of AOD, AOF, AOP, showed a similar variability of measurements, respectively $t=0.56$, $p>.05, t=0.64, p>.05, t=0.74, p>.05$. The analysis indicated that the assumption of invariance of measurements in separate groups was upheld.

\section{MGA ANALYSIS IN TERMS OF AOD}

The MGA analysis of people who are state- and action-oriented in decision-making situations showed that in both groups the intention to save was related to intention implementation with similar strength $\left(\beta_{\text {state }}=.47, p<.001\right.$ vs. $\beta_{\text {action }}=.37, p<.001 ; t=1.16$, $p>.05)$. Nevertheless, the relationship between the intention and a saving lifestyle was stronger in the group of action-oriented people than in state-oriented ones $\left(\beta_{\text {action }}=.39, p<.001\right.$ vs. $\beta_{\text {state }}=.19, p<.001$; $t=2.33, p<.001)$. An analogous result was obtained in the case of the amount of savings $\left(\beta_{\text {action }}=.24, p<.001\right.$ vs. $\left.\beta_{\text {state }}=-.02, p>.005 ; t=3.03, p<.001\right)$. The relation between intention implementation and the amount of money saved monthly was stronger in the group of state-oriented people than in the action-orient- 
ed group $\left(\beta_{\text {state }}=.27, p<.001\right.$ vs. $\beta_{\text {action }}=.06, p>.05$; $t=2.54, p<.001)$. In the case of a saving lifestyle, these relations were similar $\left(\beta_{\text {state }}=.55, p<.001\right.$ vs. $\beta_{\text {action }}=.44, p<.001 ; t=1.27, p>.05$. The moderated mediation analysis showed that intention implementation mediated the relationship between the intention and a saving lifestyle more strongly in the group of state-oriented people than in the group of actionoriented people $\left(\beta_{\text {state }}=.26, p<.001\right.$ vs. $\beta_{\text {action }}=.17$, $p<.001 ; t=1.50, p<.10)$. An analogous result was obtained in terms of the amount of money saved per month $\left(\beta_{\text {state }}=.13, p<.001\right.$ vs. $\beta_{\text {action }}=.02, p>.05$; $t=1.69, p<.05)$. The results are presented in Figure 2.

\section{MGA ANALYSIS IN TERMS OF AOF}

The second MGA analysis, which concerned both state and action oriented people's behavior exhibited after situations in which they experienced failure, showed that the intention to save money was related to intention implementation with similar strength in both groups $\left(\beta_{\text {state }}=.44, p<.001\right.$ vs. $\beta_{\text {action }}=.44, p<.001$; $t=0.06, p>.05)$. In the case of the relation between the intention and a saving lifestyle, a stronger relationship was observed in the action-oriented group than in the state-oriented one $\left(\beta_{\text {action }}=.32, p<.001\right.$ vs. $\beta_{\text {state }}=.19$, $p<.001 ; t=1.57, p<.10)$. There were no differences between the groups in terms of the strength of the relationship between the intention and the amount of savings $\left(\beta_{\text {action }}=.06, p>.05\right.$ and $\beta_{\text {state }}=.13, p<.05$; $t=0.78, p>.05)$. Further analysis showed that in the state-oriented group the relation between intention implementation and a saving lifestyle was stronger than in the action-oriented group $\left(\beta_{\text {state }}=.60, p<.001\right.$ vs. $\left.\beta_{\text {action }}=.45, p<.001 ; t=1.77, p<.05\right)$. In terms of the strength of the relationship between intention implementation and the money saved, no differences were observed $\left(\beta_{\text {state }}=.22, p<.001\right.$ vs. $\beta_{\text {action }}=.17, p<.01$; $t=0.62, p>.05)$. The analysis of moderated mediation showed that intention implementation mediated the relationship between the intention and a saving lifestyle similarly $\left(\beta_{\text {state }}=.26, p<.001\right.$ and $\beta_{\text {action }}=.20$, $p<.001 ; t=0.52, p>.05)$, as well as the relationship between the intention and the amount of saved money $\left(\beta_{\text {state }}=.10, p<.05\right.$ vs. $\beta_{\text {action }}=.07, p<.05 ; t=0.57$, $p>.05)$. The results are presented in Figure 3.

\section{MGA ANALYSIS IN TERMS OF AOP}

The third MGA analysis of state-oriented and actionoriented people in terms of activity performance showed that the intention to save was related more strongly to intention implementation in the stateoriented participants than the action-oriented ones $\left(\beta_{\text {state }}=.48, p<.001\right.$ vs. $\beta_{\text {action }}=.29, p<.001 ; t=2.29$, $p<.001)$. In the case of the relation between the intention and a saving lifestyle a stronger relation was observed in the action-oriented group compared to the state-oriented group $\left(\beta_{\text {action }}=.37, p<.001\right.$ vs. $\left.\beta_{\text {state }}=.21, p<.001 ; t=1.85, p<.10\right)$. Differences between the groups were not observed in terms of the strength of the relation between the intention and

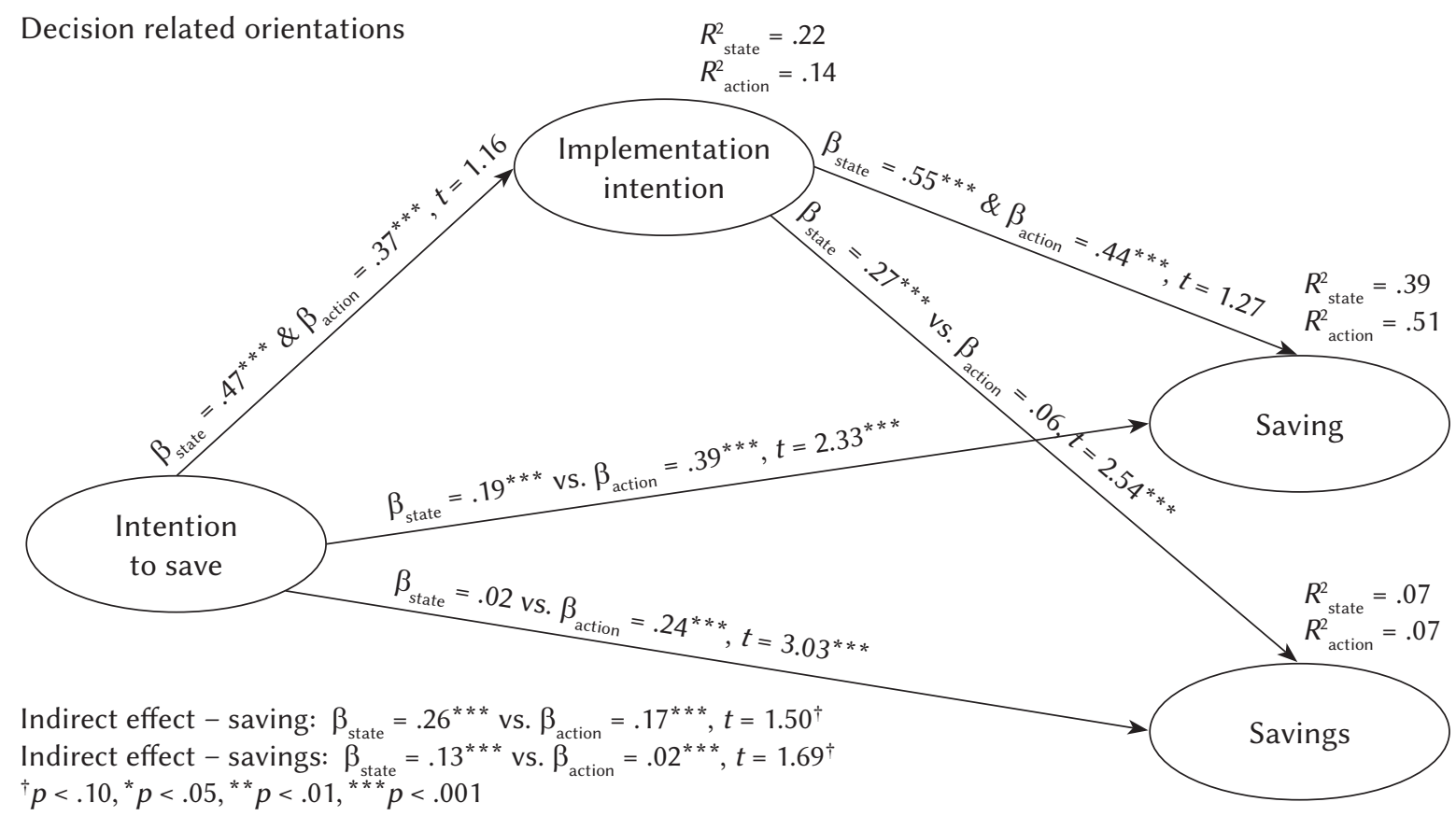

Figure 2. The moderation effects of state and action orientation during the decision making in the model of implementation intention mediation between the intention and the forms of saving. 
savings $\left(\beta_{\text {state }}=.09, p>.05\right.$ and $\beta_{\text {action }}=.11, p>.05$; $t=0.19, p>.05)$, intention implementation and a saving lifestyle $\left(\beta_{\text {state }}=.52, p<.001\right.$ and $\beta_{\text {action }}=.51$, $p<.001 ; t=0.19, p>.05)$, and also intention implementation and savings $\left(\beta_{\text {state }}=.18, p<.001\right.$ and $\left.\beta_{\text {action }}=.22, p<.001 ; t=0.47, p>.05\right)$.
The analysis of moderated mediation showed that intention implementation mediated the relationship between the intention and a saving lifestyle more strongly in the state-oriented group than in the action-oriented group $\left(\beta_{\text {state }}=.25, p<.001\right.$ vs. $\beta_{\text {action }}=.15$, $p<.001 ; t=1.70, p<.10)$. Intention implementation

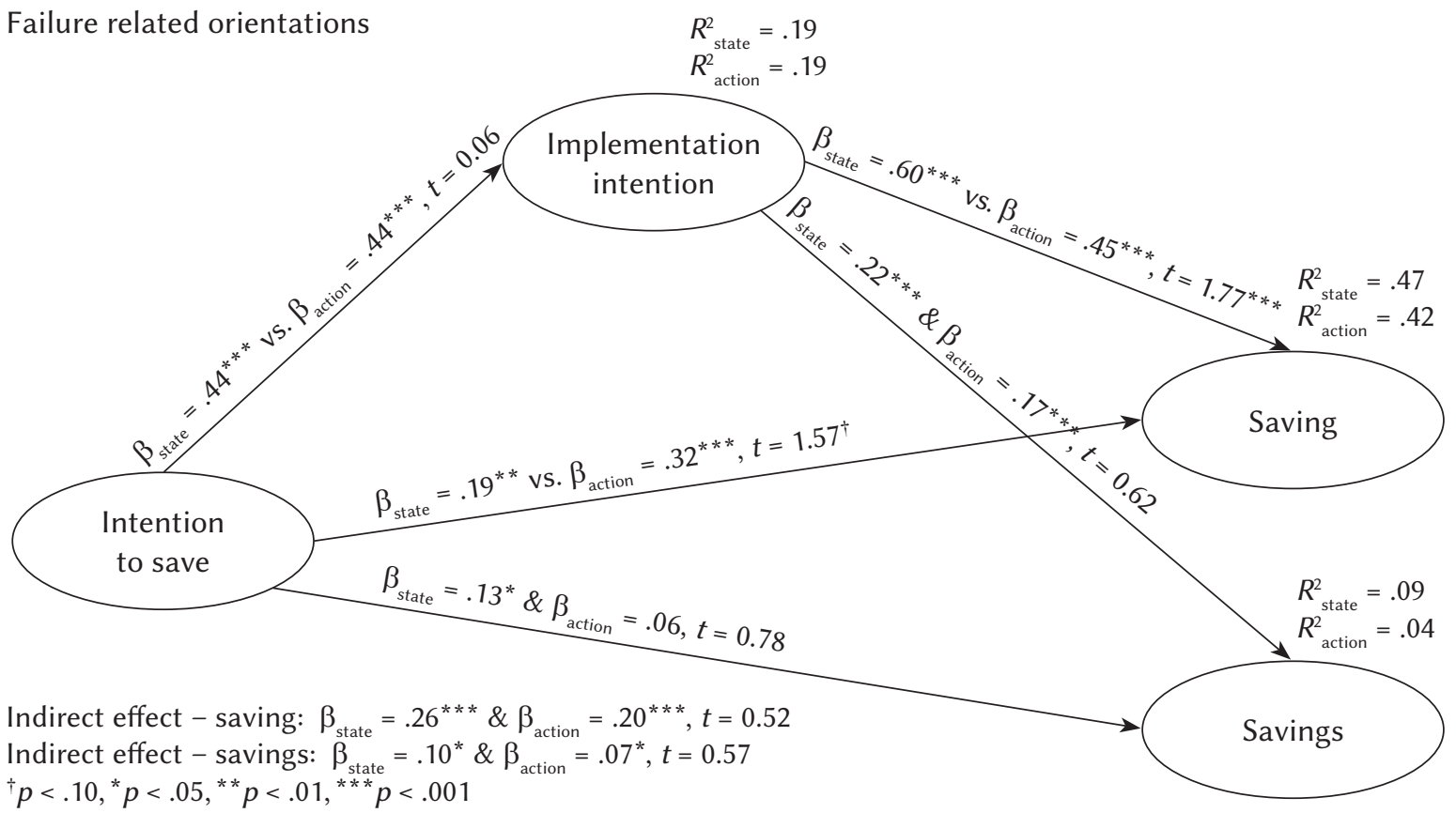

Figure 3. The moderation effects of the state and action orientation after experiencing failure in the model of implementation intention mediation between the intention and the forms of saving.

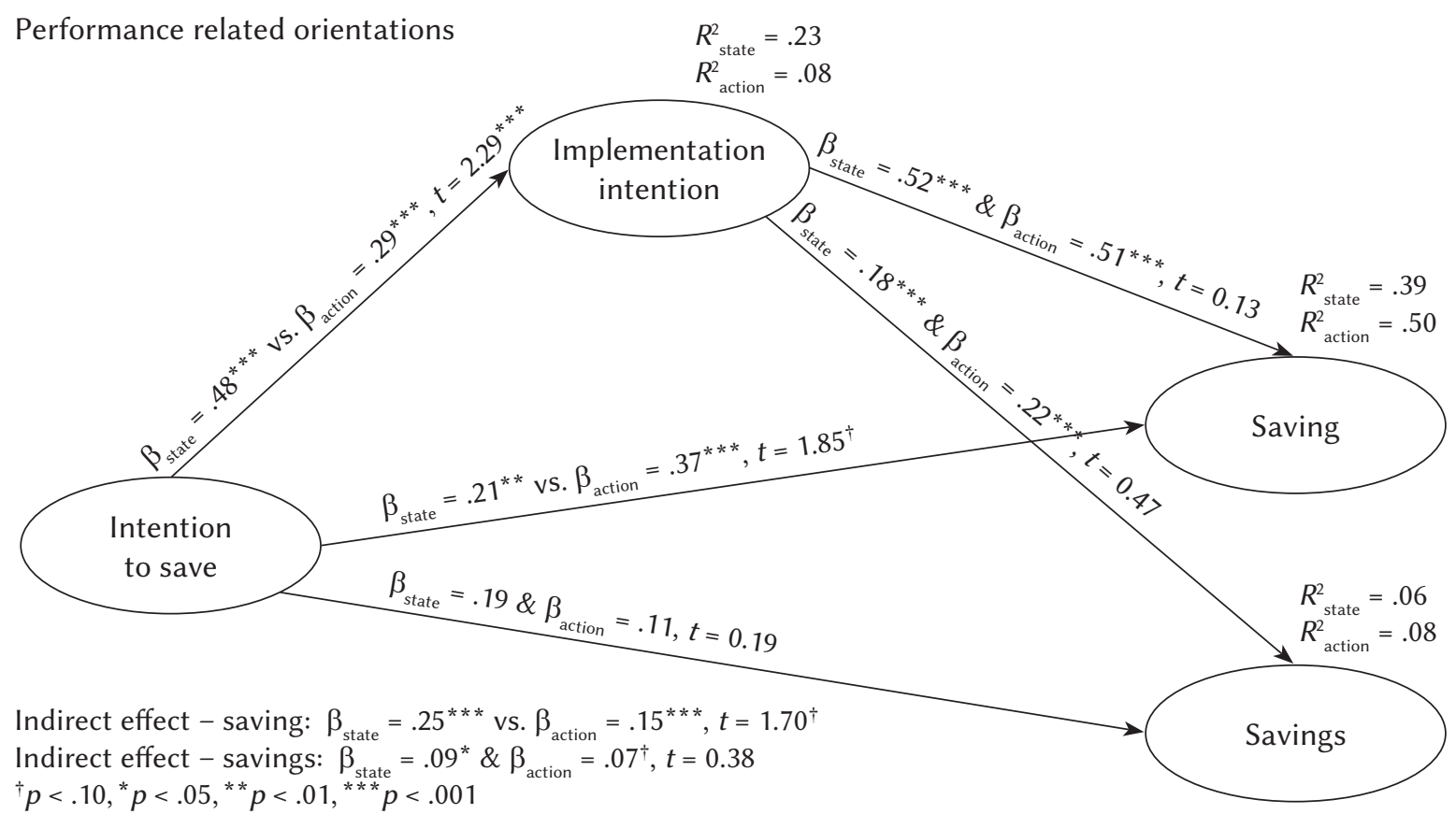

Figure 4. The moderation effects of state and action orientation during the performance of an activity in the implementation intention model between the intention and the forms of saving. 
mediated the relationship between the intention and savings similarly in both groups $\left(\beta_{\text {state }}=.09, p<.05\right.$ and $\left.\beta_{\text {action }}=.07, p<.10 ; t=0.38, p>.05\right)$. The results are presented in Figure 4.

\section{SUMMARY}

The analysis of the structural equation modeling using the PLS method showed satisfactory statistical properties in terms of models fit, as well as confirming the reliability in the context of the measurements of the tested variables and the equality of their variances in the studied groups (measurement invariance was maintained). The differences in the strength of the relationships between studied variables could be attributed to the difference between groups of state-oriented and action-oriented people, and not to the method of measuring specified variables in the models. The prediction that the mechanism of implementation intentions plays a different role in stateoriented people compared to action-oriented people was confirmed.

Two modes of functioning emerge from the collected data. The first one represents a person who fulfills desired intentions mainly due to the will to achieve them (action-oriented person). The second one encapsulates a person who performs desired behaviors mostly with methods based on planning the conditions, time, and manner of their implementation (state-oriented person). Both modes indicate the existence of regularity in functioning which allows people with high and low action control to achieve a similar level of behavioral performance.

\section{DISCUSSION}

The study confirmed the predictions. People who have difficulties with action control seem to realize their intentions mainly through planning their actions ahead, whereas people with high action control seem to do so mostly through the fact that they simply want to fulfill them. The collected observations showed that in the realization of intentional actions implementation intentions and the intention itself are of crucial importance (cf. Ajzen, 1985; Ajzen, 1991; Gollwitzer \& Sheeran, 2006). The data demonstrated that people with different levels of control over their behavior realize their intentions in a similar manner. However, they seem to be affected by two disparate psychological mechanisms. Individuals with high action control may achieve their goals because they want to do so. To them, planning of the goal realization plays an important but secondary role. By contrast, people with low action control may achieve their goals because they prepare for them. In action-oriented people, the ac- tion efficiency might be guided by willpower while state-oriented people may reach their goals through the cognitive specification of the details of the intended behavior.

\section{PERSONALITY SYSTEM INTERACTIONS THEORY}

By dint of Kuhl's personality system interaction theory (2000), we can explain the observed phenomena with the existence of four interacting personality systems. They are distinguishable from one another due to the specialization in behavioral management and separate localization in the brain (Kuhl, Quirin, \& Koole, 2015; Kuhl, 2000). The communication across these systems takes place according to the mechanisms of the experienced affect modulation (positive and negative). The postulates and mechanisms of affect modulation between personality systems are described by Kuhl (2000, 2001). For the purpose of explaining the results obtained in the study, we will use a sufficient but simplified description. $\mathrm{Mu}$ tual interactions between personality systems lead to different behaviors and states of the organism (they can determine state and action orientation). Changes in the experienced affect can activate and deactivate connections between systems. Thanks to their various interactions, we can predict the various states of the organism and behavior of a person in a vast spectrum of situations, e.g. assimilation and implementation of other people's intentions, self-regulation after the threat of death, performing analytical vs. holistic tasks, the pace of returning to equilibrium after adverse events, the quality of romantic relationships and job satisfaction (Baumann, Kuhl, \& Kazén, 2005; Kazén, Baumann, \& Kuhl, 2003, 2005; Kazén et al., 2015; Koole, Kuhl, Jostmann, \& Finkenauer, 2005; Koole, Webb, \& Sheeran, 2015; Quirin, Bode, \& Kuhl, 2011; Wojdylo, Baumann, \& Kuhl, 2017). For example, the cooperation of the object recognition system (OR - a vigilance system that is responsible for detecting every percept in the internal and external world, e.g., thing, pain, emotion, person, etc.) with the intention memory system (IM - a memory structure that allows the organism to maintain the representation of action in the memory before it can be performed), allowed by the mediating role of the "self" system (EM - an extensive memory that provides the organism representations of personal needs, values, and attitudes, as well as other aspects that are integrated in the self), enables people to identify objects in the environment that are related to the implementation of a personally important intention and the control over its execution by the system of intuitive behavior control (IBC - this system includes automated behavioral procedures based on prior learning) (Kuhl, 2000).

Each of the above-mentioned personality systems has its own specific function in the process of ex- 
ecuting behaviors and can interact differently with other systems (Kuhl, 2000, 2001). Drawing on the example of fulfilling the intention to save, we observe that state-oriented people exhibit an intention memory system which is more connected with their object recognition system. Thanks to the interaction of these systems, intention implementation, which is prepared in advance, can be recalled in appropriate circumstances and realized in the form of behavior without the participation of the "self" system resources, which are difficult to access for state-oriented people (Kuhl, 2001). When one system observes an opportunity to perform an intention, one of the other systems can follow through with it without special supervision of the system relating to the "self" resources. In state-oriented people, actions are carried out in a different mode due to the difficult access to extensive memory and, therefore, a limited ability to manage their behavior based on personal experiences, values, and attitudes contained in the self-system. Stored in the intention memory, a plan for the realization of the behavior awaits its activation, which is triggered by a signal from the object recognition system. When the circumstances included in the plan are recognized, the behavior of the person is released in a direct, automatic and independent manner from the "self" system (Gollwitzer, 1999; Kuhl, 2000). One could say that the manner of this behavior is somewhat similar to the operations of a highly sensitive, well-programmed machine.

By contrast, in action-oriented people intentions are carried out in a different way. In their case, the behavior is directed mainly by the integrated elements of the "self" system structure. We assume, therefore, that in action-oriented people, intention realization is accomplished on the basis of one's level of personal values, memories, and experiences which remain active in the extensive memory. The results indicate that these people also formulate implementation plans. Nonetheless, we believe that actionoriented people are able to continuously access the resources of the "self" system at the time of performing an action which allows them to realize their intentions from the level of personal resources and needs. The object recognition system passes information to the "self" system at first. In the next step, the "self" system forwards information further to the intention memory system which then directs intentional action, based on the level of resources which are currently active in the extensive memory. The plans of action-oriented people do not have to coordinate their current behavior, because the active intention memory system does it for them through the interaction with the "self" system. Such a manner of functioning has the quality of self-determination behavior. Strong motivation leads these people into action because it comes from their "self" (Deci \& Ryan, 2000; Koole, Schlinkert, Maldei, \& Baumann, 2018;
Ryan, Huta, \& Deci, 2008; see also: Willmott, Ryan, Sherretts, Woodfield, \& McDermott, 2018). A similar conclusion was reached in a study about the role of grit in achieving goals (Duckworth, Peterson, Matthews, \& Kelly, 2007). The authors suggested that the achievement of difficult goals depends not only on one's predispositions (i.e., talent, IQ, conscientiousness) but also the sustained and focused application of talent over time, but also perseverance and passion for one's long-term goals play a huge role in the success (Duckworth et al., 2007).

\section{LIMITATIONS AND DIRECTIONS FOR FUTURE RESEARCH}

Our studies are fully based on correlational research. Therefore, we recommend that future research examine our predictions in an experimental setup. Additionally, all the data used in the study were selfreported, and so might be biased, especially when it comes to the amount of saved money. As shown by Peetz and Buehler (2009), people's savings goals are not consistent with the amount that they actually spend and save and savings estimation tends to be biased (e.g. prediction bias). Thus, the participants of our study could have over- or under-estimated the amount of their savings. Therefore, future studies should operationalize savings as the precise amount of money saved (e.g. last month, see Study 2), which could be less prone to bias than general estimation. Moreover, the study participants underrepresented men and had a wide age range. The future study group should be gender-balanced and homogeneous when it comes to age (i.e. consist of people in the same developmental period). It would also be interesting to explore how the process of action-state orientation develops with age and how it affects the mechanisms of intention implementation and one's quality of life in a longitudinal study. Regardless of the limitations, the observed effect provided us with an interesting description of people's behavior. It appears highly promising to try to replicate these effects in the areas in which action control is crucial in terms of achieving personal satisfaction and social benefits. We believe that good examples of areas where similar patterns of behavior can be observed are nutrition and health behaviors (Schwarzer, 2008) as well as education and work (Ryan et al., 2008). It would also be interesting to assess whether the obtained effects are universal and refer not only to health-related and socially desirable behaviors. Pfister, Wirth, Schwarz, Steinhauser, and Kunde (2016) observed that violating a rule comes with profound conflict for the rule-breaker (Pfister et al., 2016; Pfister, Wirth, Weller, Foerster, \& Schwarz, 2019). That suggests that rule-violation intention may come under different mechanisms (cf. Pfister et al., 2016; 
Pfister et al., 2019). We suppose that additional mechanisms resolving the conflict may be involved. Additionally, succeeding in achieving one's goals comes at a price for state-oriented people. Their success is based on constant planning and monitoring of their actions, which consumes a lot of their resources. As Schlinkert and Koole (2018) proved, action-state orientation plays an important role in maintaining one's energetic resources. State-oriented people suffer more than action-oriented people from the draining effects of demands (Schlinkert \& Koole, 2018). We recommend that future studies focus on identifying the factors that could protect state-oriented people from excessive exertion and improve their quality of life so that their competence growth would not be as challenging as it is.

\section{CONCLUSIONS}

People differ in their level of achievement. Those who have problems with controlling their behavior do not have to be necessarily doomed to failure. They can achieve their aspirations and goals through deliberate planning methods, whereas people who are not affected by the problem of behavior control can accomplish their goals due to their willpower. These apparent differences encourage reflection on financial counseling, coaching, and psychotherapy (Delgadillo, 2014; Kuhl, Kazén, \& Koole, 2006). It seems reasonable to strengthen people's natural predispositions to act efficiently. People with low action control should be subjected to mindfulness and time management training, e.g. in an implementing manner. On the other hand, people with high action control would benefit most from techniques enabling them to use and listen to their internal resources.

\section{ENDNOTE}

$1 \mathrm{GoF}$ - model fit indicator, the square root of the product between what they refer to as the average communality index and the average $R^{2}$ for the model (Tenenhaus et al., 2005); SRMR - model fit indicator, standardized root mean squared residual; SMAR - model fit indicator, standardized mean absolute residual; AVIF - average block variance inflation factor; AFVIF - average variance inflation factor (Kock \& Mayfield, 2015).

\section{References}

Ajzen, I. (1985). From intentions to actions: A theory of planned behavior. In J. Kuhl \& J. Beckmann (Eds.), Action control: From cognition to behavior (pp. 11-39). Berlin: Springer.
Ajzen, I. (1991). The theory of planned behavior. Orgnizational Behavior and Human Decision Processes, 50, 179-211. https://doi.org/10.1016/07495978(91)90020-T

Baron, R. M., \& Kenny, D. A. (1986). The moderator-mediator variable distinction in social psychological research: Conceptual, strategic, and statistical considerations. Journal of Personality and Social Psychology, 51, 1173-1182. https://doi. org/10.1037/0022-3514.51.6.1173

Baumann, N., \& Kuhl, J. (2005). How to resist temptation: The effects of external control versus autonomy support on self-regulatory dynamics. Journal of Personality, 73, 443-470. https://doi. org/10.1111/j.1467-6494.2005.00315.x

Baumann, N., Kuhl, J., \& Kazén, M. (2005). Left-hemispheric activation and self-infiltration: Testing a neuropsychological model of internalization. Motivation and Emotion, 29, 135-163. https://doi. org/10.1007/s11031-005-9439-x

Baumeister, R. F. (2002). Yielding to temptation: Selfcontrol failure, impulsive purchasing, and consumer behavior. Journal of Consumer Research, 28, 670-676. https://doi.org/10.1086/338209

Baumeister, R. F., \& Vohs, K. D. (2007). Self-regulation, ego depletion, and motivation. Social and Personality Psychology Compass, 1, 115-128. https://doi. org/10.1111/j.1751-9004.2007.00001.x

Deci, E. L., \& Ryan, R. M. (2000). The "what" and "why" of goal pursuits: Human needs and the self-determination of behavior. Psychological Inquiry, 11, 227268. https://doi.org/10.1207/S15327965PLI1104_01

Delgadillo, L. M. (2014). Financial clarity: Education, literacy, capability, counseling, planning, and coaching. Family and Consumer Sciences Research Journal, 43, 18-28. https://doi.org/10.1111/fcsr. 12078

Dholakia, U., Tam, L., Yoon, S., \& Wong, N. (2016). The ant and the grasshopper: Understanding personal saving orientation of consumers. Journal of Consumer Research, 43, 134-155. https://doi.org/10.1093/ jcr/ucw004

Drever, A. I., Odders-White, E., Kalish, C. W., ElseQuest, N. M., Hoagland, E. M., \& Nelms, E. N. (2015). Foundations of financial well-being: Insights into the role of executive function, financial socialization, and experience-based learning in childhood and youth. Journal of Consumer Affairs, 49, 13-38. https://doi.org/10.1111/joca. 12068

Duckworth, A. L., Peterson, C., Matthews, M. D., \& Kelly, D. R. (2007). Grit: Perseverance and passion for long-term goals. Journal of Personality and Social Psychology, 92, 1087-1101. https://doi. org/10.1037/0022-3514.92.6.1087

Faber, R. J., \& Vohs, K. D. (2011). Self-regulation and spending: Evidence from impulsive and compulsive buying. In K. D. Vohs \& R. F. Baumeister (Eds.), Handbook of self-regulation: Research, theory, and applications (pp. 537-550). New York: The Guilford Press. 
Gollwitzer, P. M. (1999). Implementation intentions: Strong effects of simple plans. American Psychologist, 54, 493-503. https://doi.org/10.1177/0146167207311201

Gollwitzer, P. M., \& Sheeran, P. (2006). Implementation intentions and goal achievement: A meta-analysis of effects and processes. Advances in Experimental Social Psychology, 38, 69-119. https://doi.org/10.1016/ S0065-2601(06)38002-1

Goschke, T., \& Kuhl, J. (1993). Representation of intentions: Persisting activation in memory. Journal of Experimental Psychology: Learning, Memory, and Cognition, 19, 1211-1226. https://doi.org/10. 1037/0278-7393.19.5.1211

lacobucci, D. (2010). Structural equations modeling: Fit indices, sample size, and advanced topics. Journal of Consumer Psychology, 20, 90-98. https:// doi.org/10.1016/j.jcps.2009.09.003

Kazén, M., Baumann, N., \& Kuhl, J. (2003). Self-infiltration vs. self-compatibility checking in dealing with unattractive tasks: The moderating influence of state vs. action orientation. Motivation and Emotion, 27, 157-197. https://doi.org/10.1023/A:1025043530799

Kazén, M., Baumann, N., \& Kuhl, J. (2005). Self-regulation after mortality salience: National pride feelings of action-oriented German participants. European Psychologist, 10, 218-228. https://doi.org/ 10.1027/1016-9040.10.3.218

Kazén, M., Kuhl, J., \& Leicht, E. M. (2014). When the going gets tough...: Self-motivation is associated with invigoration and fun. Psychological Research, 79, 1064-1076. https://doi.org/10.1007/s00426-0140631-z

Kazén, M., Kuhl, J., \& Quirin, M. (2015). Personality interacts with implicit affect to predict performance in analytic versus holistic processing. Journal of Personality, 83, 251-261. https://doi.org/10.1111/jopy. 12100

Kock, N. (2010). Using WarpPLS in e-collaboration studies: An overview of five main analysis steps. International Journal of e-Collaboration, 6, 1-12. https://doi.org/10.4018/jec.2010100101

Kock, N. (2011). Using WarpPLS in e-collaboration studies: Mediating effects, control and second order variables, and algorithm choices. International Journal of e-Collaboration, 7, 1-13. https://doi. org/10.4018/jec.2011070101

Kock, N. (2014a). A note on how to conduct a factorbased PLS-SEM analysis. International Journal of e-Collaboration, 11, 1-9. https://doi.org/10.4018/ ijec.2015070101

Kock, N. (2014b). Advanced mediating effects tests, multi-group analyses, and measurement model assessments in PLS-based SEM. International Journal of e-Collaboration, 10, 1-13. https://doi.org/10.4018/ ijec.2014010101

Kock, N. (2014c). Stable P value calculation methods in PLS-SEM. Laredo, TX: ScriptWarp Systems. https:// doi.org/DOI:10.13140/2.1.2215.3284
Kock, N., \& Gaskins, L. (2016). Simpson's paradox, moderation, and the emergence of quadratic relationships in path models: An information systems illustration. International Journal of Applied Nonlinear Science, 2, 200-234. https://doi.org/10.1109/ ICUMT.2009.5345351

Kock, N., \& Lynn, G. S. (2012). Lateral collinearity and misleading results in variance-based SEM: An illustration and recommendations. Journal of the Association for Information Systems, 13, 546-580. https://doi.org/10.17705/1jais.00302

Kock, N., \& Mayfield, M. (2015). PLS-based SEM AIgorithms: The good neighbor assumption, collinearity, and nonlinearity. Information Management \& Business Review, 7, 113-130.

Koole, S. L., Kuhl, J., Jostmann, N. B., \& Finkenauer, C. (2005). Self-regulation in interpersonal relationships: The case of action versus state orientation. In K. D. Vohs \& E. J. Finkel (Eds.), Intrapersonal and interpersonal processes: How they relate ( $\mathrm{pp}$. 1-39). New York: Guilford.

Koole, S. L., Schlinkert, C., Maldei, T., \& Baumann, N. (2018). Becoming who you are: An integrative review of self-determination theory and personality systems interactions theory. Journal of Personality, 87, 15-36. https://doi.org/10.1111/jopy. 12380

Koole, S. L., Webb, T. L., \& Sheeran, P. L. (2015). Implicit emotion regulation: Feeling better without knowing why. Current Opinion in Psychology, 3, 6-10. https://doi.org/10.1016/j.copsyc.2014.12.027

Kuhl, J. (1981). Motivational and functional helplessness: The moderating effect of state versus action orientation. Journal of Personality and Social Psychology, 40, 155-170. https://doi.org/10.1037/00223514.40.1.155

Kuhl, J. (1984). Volitional aspects of achievement motivation and learned helplessness: Toward a comprehensive theory of action control. Progress in Experimental Personality Research, 13, 99-171. https:// doi.org/10.1016/B978-0-12-541413-5.50007-3

Kuhl, J. (2000). A Functional-design approach to motivation and self-regulation: The dynamics of personality systems interactions. In M. Boekaerts, P. R. Pintrich, \& M. Zeidner (Eds.), Handbook of self-regulation (pp. 111-169). San Diego, CA: Academic Press.

Kuhl, J. (2001). A functional approach to motivation. In A. Efklides, J. Kuhl, \& R. M. Sorrentino (Eds.), Trends and prospects in motivation research (pp. 239-268). Dordrecht: Springer.

Kuhl, J., \& Beckmann, J. (1994). Volition and personality: Action versus state orientation. Seattle: Hogrefe \& Huber Publishers.

Kuhl, J., Kazén, M., \& Koole, S. L. (2006). Putting selfregulation theory into practice: A user's manual. Applied Psychology, 55, 408-418. https://doi.org/10. 1111/j.1464-0597.2006.00260.x

Kuhl, J., Quirin, M., \& Koole, S. L. (2015). Being someone: The integrated self as a neuropsychological 
system. Social and Personality Psychology Compass, 9, 115-132. https://doi.org/10.1111/spc3.12162

Loibl, C., Grinstein-Weiss, M., Zhan, M., \& Red Bird, B. (2010). More than a penny saved: Long-term changes in behaviour among savings program participants. Journal of Consumer Affairs, 44, 98-126. https://doi.org/10.1111/j.1745-6606.2010.01159.x

Maier, S. F., \& Seligman, M. E. P. (2016). Learned helplessness at fifty: Insights from neuroscience. Psychological Review, 123, 340-367. https://doi.org/10.1037/ rev0000033

Marszał-Wiśniewska, M. (2002). Adaptacja Skali Kontroli Działania J. Kuhla (ACS-90) [Adaptation of Kuhl's Action Control Scale (ACS-90)]. Studia Psychologiczne, 40, 77-102.

Muraven, M., Tice, D. M., \& Baumeister, R. F. (1998). Self-control as a limited resource: Regulatory depletion patterns. Journal of Personality and Social Psychology, 74, 774-789. https://doi.org/10.1037/00223514.74.3.774

Pearl, J. (2009). Causality: Models, reasoning and inference (2nd ed.). New York: Cambridge University Press.

Peetz, J., \& Buehler, R. (2009). Is there a budget fallacy? The role of savings goals in the prediction of personal spending. Personality and Social Psychology Bulletin, 35, 1579-1591. https://doi.org/10. 1177/0146167209345160

Pfister, R., Wirth, R., Schwarz, K., Steinhauser, M., \& Kunde, W. (2016). Burdens of non-conformity: Motor execution reveals cognitive conflict during deliberate rule violations. Cognition, 147, 93-99. https://doi.org/10.1016/j.cognition.2015.11.009

Pfister, R., Wirth, R., Weller, L., Foerster, A., \& Schwarz, K. A. (2019). Taking shortcuts: Cognitive conflict during motivated rule-breaking. Journal of Economic Psychology, 71, 138-147. https:// doi.org/10.1016/j.joep.2018.06.005

Prochaska, J. O., Wright, J. A., \& Velicer, W. F. (2008). Evaluating theories of health behavior change: A hierarchy of criteria applied to the transtheoretical model. Applied Psychology, 57, 561-588. https://doi.org/10.1111/j.1464-0597.2008.00345.x

Quirin, M., Bode, R. C., \& Kuhl, J. (2011). Recovering from negative events by boosting implicit positive affect. Cognition and Emotion, 25, 559-570. https:// doi.org/10.1080/02699931.2010.536418

Ryan, R. M., Huta, V., \& Deci, E. L. (2008). Living well: A self-determination theory perspective on eudaimonia. Journal of Happiness Studies, 9, 139-170. https://doi.org/10.1007/s10902-006-9023-4

Sarstedt, M., Henseler, J., \& Ringle, C. M. (2011). Multigroup analysis in partial least squares (PLS) path modeling: Alternative methods and empirical results. Advances in International Marketing, 22, 195-218. https://doi.org/10.1108/S14747979(2011)0000022012

Sarstedt, M., Ringle, C. M., \& Hair, J. F. (2017). Treating unobserved heterogeneity in PLS-SEM: A multi- method approach. In H. Latan \& R. Noonan (Eds.), Partial Least Squares Path Modeling (pp. 197-217). Cham: Springer.

Schlinkert, C., \& Koole, S. L. (2018). Dealing with life demands: Action-state orientation moderates the relation between demanding conditions and drops in body vitality. Motivation Science, 4, 118-136. http://dx.doi.org/10.1037/mot0000078

Schwarzer, R. (2008). Modeling health behavior change: How to predict and modify the adoption and maintenance of health behaviors. Applied Psychology, 57, 1-29. https://doi.org/10.1111/j.14640597.2007.00325.x

Seligman, M. E. P., \& Maier, S. F. (1967). Failure to escape traumatic shock. Journal of Experimental Psychology, 74, 1-9. https://doi.org/10.1037/h0024514

Sotiropoulos, V., \& d'Astous, A. (2013). Attitudinal, selfefficacy, and social norms determinants of young consumers' propensity to overspend on credit cards. Journal of Consumer Policy, 36, 179-196. https://doi. org/10.1007/s10603-013-9223-3

Steinmetz, H., Knappstein, M., Ajzen, I., Schmidt, P., \& Kabst, R. (2016). How effective are behavior change interventions based on the theory of planned behavior? Zeitschrift Für Psychologie, 224, 216-233. https://doi.org/10.1027/2151-2604/a000255

Taylor, M. P., Jenkins, S. P., \& Sacker, A. (2011). Financial capability and psychological health. Journal of Economic Psychology, 32, 710-723. https://doi. org/10.1016/j.joep.2011.05.006

Tenenhaus, M., Vinzi, V. E, Chatelin, Y. M., \& Lauro, C. (2005). PLS path modeling. Computational Statistics \& Data Analysis, 48, 159-205. https://doi.org/10.1016/j. csda.2004.03.005

von Stumm, S., Fenton O'Creevy, M., \& Furnham, A. (2013). Financial capability, money attitudes and socioeconomic status: Risks for experiencing adverse financial events. Personality and Individual Differences, 54, 344-349. https://doi.org/10.1016/j. paid.2012.09.019

Willmott, D., Ryan, S., Sherretts, N., Woodfield, R., \& McDermott, D. (2018). Motivation: A critical consideration of Freud and Rogers' seminal conceptualisations. Polish Psychological Bulletin, 49, 229-234. https://doi.org/10.24425/119490

Wojdylo, K., Baumann, N., \& Kuhl, J. (2017). The firepower of work craving: When self-control is burning under the rubble of self-regulation. PLoS One, 12, 1-17. https://doi.org/10.1371/journal.pone.0169729

Worthy, S. L., Jonkman, J., \& Blinn-Pike, L. (2010). Sensation-seeking, risk-taking, and problematic financial behaviors of college students. Journal of Family and Economic Issues, 31,161-170. https://doi. org/10.1007/s10834-010-9183-6

Xiao, J. J., Chatterjee, S., \& Kim, J. (2014). Factors associated with financial independence of young adults. International Journal of Consumer Studies, 38, 394-403. https://doi.org/10.1111/ijcs. 12106 